\title{
Innate Immune Cells' Contribution to Systemic Lupus Erythematosus
}

\author{
Andrés A. Herrada ${ }^{1}$, Noelia Escobedo ${ }^{1}$, Mirentxu Iruretagoyena ${ }^{2}$, \\ Rodrigo A. Valenzuela ${ }^{3,4}$, Paula I. Burgos ${ }^{2}$, Loreto Cuitino ${ }^{3,5 *}$ and Carolina Llanos ${ }^{2 *}$ \\ 1 Lymphatic and Inflammation Research Laboratory, Facultad de Ciencias de la Salud, Instituto de Ciencias Biomédicas, \\ Universidad Autónoma de Chile, Talca, Chile, ${ }^{2}$ Departamento de Inmunología Clínica y Reumatología, Escuela de Medicina, \\ Pontificia Universidad Católica de Chile, Santiago, Chile, ${ }^{3}$ Laboratorio de Enfermedades Autoinmunes Oculares y Sistémicas, \\ Departamento de Oftalmología, Facultad de Medicina, Universidad de Chile, Santiago, Chile, ${ }^{4}$ Departamento de Ciencias \\ Químicas y Biológicas, Facultad de Salud, Universidad Bernardo O’Higgins, Santiago, Chile, ${ }^{5}$ Servicio de Oftalmología, \\ Hospital Clínico Universidad de Chile, Santiago, Chile
}

Systemic lupus erythematosus (SLE) is a chronic autoimmune disease characterized by the presence of autoantibodies against nuclear antigens, immune complex deposition, and tissue damage in the kidneys, skin, heart and lung. Because of the pathogenic role of antinuclear antibodies and autoreactive T cells in SLE, extensive efforts have been made to demonstrate how B cells act as antibody-producing or as antigen-presenting cells that can prime autoreactive $T$ cell activation. With the discovery of new innate immune cells and inflammatory mediators, innate immunity is emerging as a key player in disease pathologies. Recent work over the last decade has highlighted the importance of innate immune cells and molecules in promoting and potentiating SLE. In this review, we discuss recent evidence of the involvement of different innate immune cells and pathways in the pathogenesis of SLE. We also discuss new therapeutics targets directed against innate immune components as potential novel therapies in SLE.

Keywords: lupus (SLE), innate immunity, dendritic cells, macrophage-cell, innate lymphoid cell

\section{INTRODUCTION}

Systemic lupus erythematosus (SLE) is a systemic autoimmune disease that affects 20-50 of every 100,000 individuals and whose etiology remains elusive. Whereas early symptoms most frequently involve the skin and joints, disease morbidity and mortality are usually associated with cardiovascular events driven by chronic inflammation, and damage to major organs, particularly the kidneys, the nervous system, hematopoietic organs, and infections derived from immunosuppressant treatments. SLE is also characterized by a myriad of immune system aberrations, including pathogenic autoantibody production and immune complex deposition, and immune system infiltration and inflammation within damaged organs. The main autoantibodies present in the serum of SLE patients are directed against nuclear components [double-stranded DNA (dsDNA), ribonucleoproteins, histones and others]. Systemic tissue damage may arise as a consequence of inflammation caused by direct autoantibody-mediated tissue damage and the deposition of complement-fixing immune complexes (1-3).

Various immune cells and inflammatory mediators have been shown to be harmful players in SLE, especially dysfunctional $\mathrm{T}$ and $\mathrm{B}$ cells. Hormonal, environmental, and genetic factors are linked to the loss of B- or T-cell tolerance to self-antigens, triggering the activation of both the innate and the adaptive immune system $(4,5)$. To date, there are no curative treatments for SLE, 
but current pharmacological approaches for management of SLE have included corticosteroids and immunosuppressive drugs. These drugs can control disease activity, although they have serious, potentially fatal, side effects. B-cell-targeted therapies, including B-cell depletion and blockage of B-cell survival factors, such as B-lymphocyte stimulator (BLyS), have also been developed. While safer than other therapies, B cell-targeted therapies efficacy is still controversial (6). Thus, some studies have shown improvement in lupus while other studies have failed to show any clinical improvement $(7,8)$. Trial design methodologies including patient's selection, the use of steroids, or short follow up time, can in part explain these discrepancies (9). The results from several trials that are currently underway might clarify these issues (9). Other immune system modulating strategies, including blocking monoclonal antibodies and fusion proteins targeting type 1 IFNs or pro-inflammatory cytokines, such as IL-12 and IL-23, are currently in development (1). Table 1 summarizes the current treatments for SLE.

The innate immune system consists of immune cells, including macrophages, neutrophils, dendritic cells (DCs), basophils, and innate lymphoid cells (ILCs), that circulate in blood or reside in tissues and are poised to respond to pathogens or inflammatory stimuli. Some innate immune cells, such as DCs, can migrate to lymphoid tissues to invoke $\mathrm{T}$ and $\mathrm{B}$ cell responses and also interface with the other cells in the skin and mucosal epithelia that can produce different cytokines and antimicrobial peptides to influence tissue homeostasis and repair. Recently, the innate immune system has been implicated as a key player in the pathogenesis of SLE. In this review, we will focus on cellular and molecular components of the innate immunity in SLE pathogenesis. We will summarize the current pre-clinical and clinical studies that aim to target innate immunity in SLE.

\section{INNATE IMMUNITY IN SLE}

\section{Macrophages}

Due to the presence of self-reactive IgG antibodies, SLE development has been commonly associated with dysfunctional adaptive immune responses, especially B-cell responses. This paradigm, however, is shifting, due to rapid advances showing an important role of innate immunity in SLE pathogenesis (24). Studies in patients with SLE and animal models show multiple aberrations in the activation status and secretory functions of circulating and tissue-infiltrating macrophages (25). Such aberrations may be associated with deregulation of Tcell function and autoantibody production in SLE (24, 25). Specifically, a role for macrophages in the pathogenesis of SLE was first proposed following the discovery that SLE macrophages were defective in their ability to clear apoptotic cell debris, thus prolonging exposure of potential auto-antigens to the adaptive immune cells $(26,27)$. Moreover, activated macrophages are classically categorized in two main groups: classically-activated macrophages (M1), induced by the presence of IFN $\gamma$ and LPS, that are involved in inflammation and tissue destruction; or alternatively-activated macrophages (M2), induced by IL-4 or IL-13, cytokines that are involved in tissue repair (28). Gene expression profiles from myeloid cells derived from SLE patients and healthy controls have revealed differences in genes that play an important role in macrophage activation and polarization: STAT1 and SOCS3 for M1 are increased; and STAT3, STAT6, and CD163 for M2 are decreased (29). Further, monocyte-derived macrophages from SLE patients show reduced CD163 (M2 marker) and increased CD86 (M1 marker) expression, compared to healthy controls, after treatment with apoptotic cells (30). Thus, M1 and M2 profiles are altered in human SLE patients.

Functional studies in mouse models have shown different roles for M1 and M2 macrophages in SLE. Macrophage depletion in a pharmacological induced-lupus mouse model increases SLE severity (31). Interestingly, adoptive transfer of M2 macrophages reduces SLE severity, but transfer of M1 macrophages increases SLE activity. Thus, M1 macrophages promote tissue damage, while M2 macrophages participate in tissue healing in SLE (31). It seems that skewed M1/M2 responses are also involved in kidney damage during SLE. Nearly $60 \%$ of SLE patients develop kidney involvement at some point of the disease, known as lupus nephritis (32). It has been recently demonstrated that, after transient ischemia/reperfusion injury, a non-resolving inflammation develops in mice that are susceptible to developing SLE-like disease. This inflammation is characterized by an increase of M1 vs. M2 macrophages that infiltrate the kidney (33). In summary, defective phagocytosis of apoptotic cells and/or abnormal M1 vs. M2 macrophage polarization can mediate adaptive immune activation and promote autoimmune damage in SLE, suggesting that drugs capable of modulate macrophage function could be a good alternative to develop a strategy against SLE (30).

\section{Neutrophils}

Neutrophils, the most abundant leukocytes in human blood, have been recently linked with SLE. Neutrophils in SLE have abnormal function, including reduced phagocytosis capabilities (34), reduced ability to be cleared by the C1q/calreticulin/CD91mediated apoptotic pathway (35), and increased oxidative activity (36). Another process that is affected in neutrophils from SLE patients or Lupus-mice models is NETosis (37). First described in 2004, NETosis is a specific form of cell death, characterized by the release of decondensed chromatin coated with antimicrobial, granular proteins into the extracellular space. These neutrophil-derived extracellular traps (NETs) trap and inactivate pathogens (38), but could but also be a source of immunogenic DNA, histones, and neutrophil proteins. In SLE, NETosis is accelerated by the presence of anti-ribonucleoprotein complexes and circulating apoptotic microparticles, which, in turn, activate other immune cell types such as plasmacytoid DCs (pDCs) (39-41). In fact, low-density granulocytes, a specific subset of neutrophils found in SLE patients, show increased NET formation, and these neutrophils are able to infiltrate the kidneys and skin (42). Moreover, patients with active SLE lesions have impaired degradation of NETs due to the presence of DNase I inhibitors and anti-NET antibodies (43). Mechanistically, NETs enriched in oxidized mitochondrial DNA can stimulate production of type I IFNs by direct interaction with the DNA sensor STING (44). In this context, further analysis must be done to establish NETosis as a new potential biomarker or tissue damage predictor in SLE (45). 
TABLE 1 | Current available treatments in systemic lupus erythematosus.

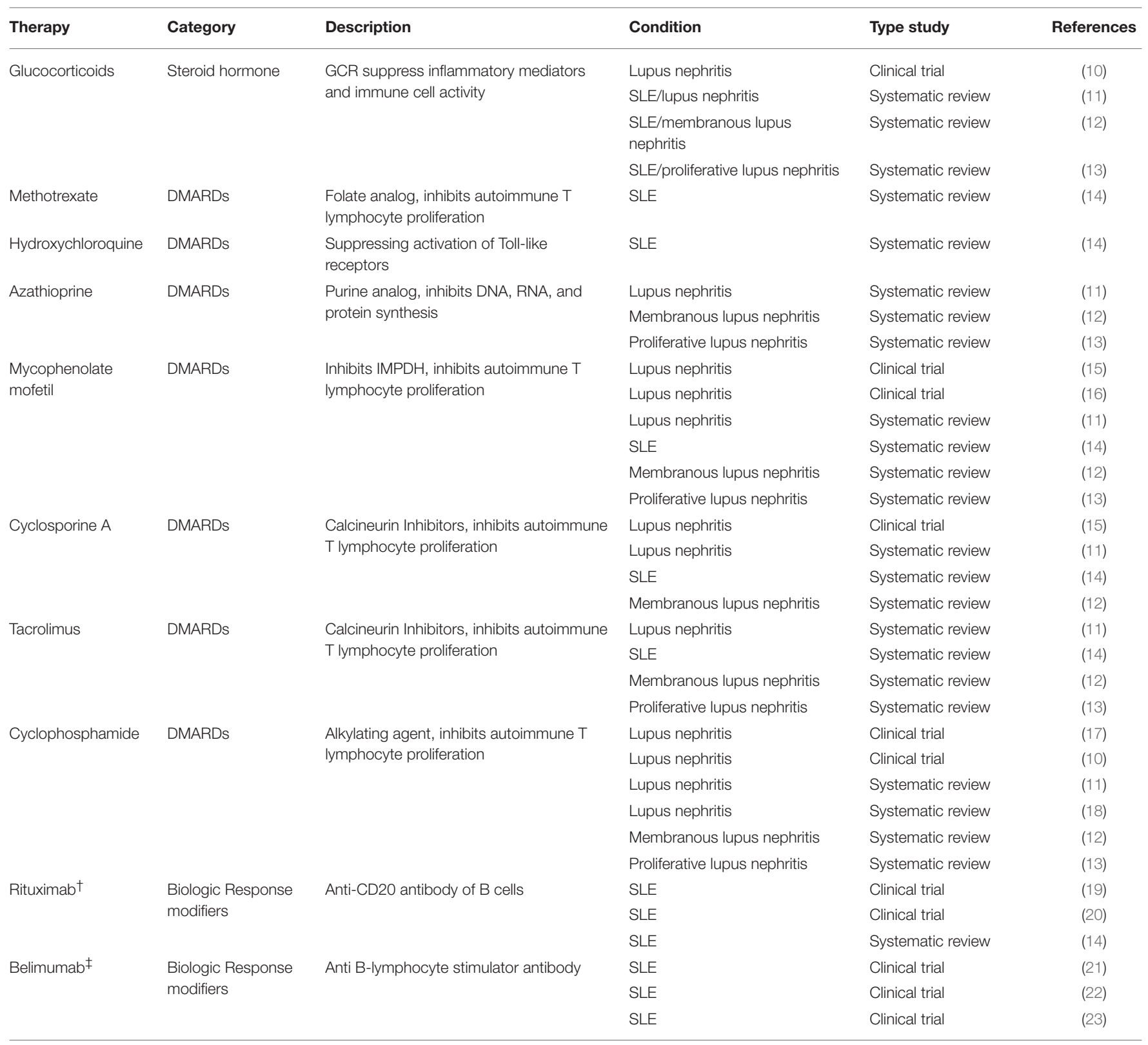

DMARDs, Non-biologic disease-modifying antirheumatic drugs; SLE, Systemic Lupus eryhematosus; GCR, glucocorticoid receptor; IMPDH, inosin monophosphate dehydrogenase; IVIg, Intrevenous immunoglobulin.

${ }^{\dagger}$ Off-label used and recommended by clinical guidelines for in SLE and Lupus nephritis. ${ }^{\ddagger}$ Approved by FDA.

\section{Dendritic Cells}

In the last decade, our group and others have identified DCs as essential players in the mechanisms underlying SLE, making them attractive therapeutic targets for the fine-tuning of the immune system. Mature DCs can activate $\mathrm{T}$ cells. In contrast, tolerogenic (immature) DCs or monocytes, cells able to differentiate to DCs, can promote T-cell hyporesponsiveness, and induce immune tolerance (46). Therefore, tolerogenic DCs or monocytes have emerged as an attractive therapeutic target, because they can induce antigenspecific tolerance without provoking general, widespread immunosuppression. This targeting strategy may reduce or eliminate the development of increased susceptibility to pathogens and opportunistic infections, a commonly-observed side effect of the traditional immunosuppressant drugs currently used in SLE therapy (47-49).

One of the key enzymes that controls monocyte and DC function is heme oxygenase-1 (HO-1), which catalyzes the degradation of the heme group into biliverdin, carbon monoxide $(\mathrm{CO})$, and free iron $\left(\mathrm{Fe}^{2+}\right)$. These byproducts have immunosuppressive and anti-inflammatory activities. In normal conditions, HO-1 is highly expressed in monocytes and DCs, 
and the products of $\mathrm{HO}-1$ catalysis can contribute to improve tolerance during organ transplantation. HO-1 expression is reduced in monocytes but not in DCs or $\mathrm{CD}^{+} \mathrm{T}$ cells from SLE patients or in healthy controls (50). Therefore, HO-1 deregulation may be involved in the initial steps of SLE pathogenesis, rather than in disease progression. HO-1 modulation, as well as CO administration, has emerged as a potential therapy for SLE (51). Genetic or pharmacological modulation of HO-1 and delivery of $\mathrm{CO}$ ameliorates disease progression in experimental autoimmune models, such as experimental autoimmune encephalomyelitis, type- 1 diabetes, and SLE (52). HO-1 and/or CO can modulate DC and monocyte function (53). $\mathrm{CO}$ exposure also decreases $\mathrm{B}_{2} 20^{+}, \mathrm{CD}^{+}$and $\mathrm{CD}^{+} \mathrm{T}$ cells in the kidneys and lungs, as well as serum levels of antinuclear antibodies (ANA) of lupus nephritis patients (54). It is also important to mention, as an alternative, noninvasive strategy, a nutritional therapy with extra virgin olive oil increases HO-1 and Nrf-2 protein expression in animal models of SLE and diminishes activation of JAK/STAT, MAPK, and NF-kB pathways that can drive proinflammatory cytokine and chemokine production from many immune cell types (55).

pDCs, first described as the main source of IFNs after viral infection (56), have been linked to SLE development. Early studies showed increased serum levels of IFN $\alpha$ in SLE patients $(57,58)$. Moreover, genome-wide analysis has identified the IFN $\alpha$ pathway among susceptibility alleles $(59,60)$. The IFN $\alpha$ inducer, consisting of anti-dsDNA antibodies, and DNA in complex, was identified in the late 1990s (61). pDCs were subsequently identified as the essential origin of IFN $\alpha$ production in SLE (62). IFN $\alpha$ release by pDCs occurred mainly at early-stages during disease, since pDCs from late-stages disease are unable to produce IFN $\alpha$ in the MRL/Mp-Faslpr (lpr) lupus mouse model (63). pDCs numbers are diminished in blood of SLE patients, but pDCs accumulate in the inflamed or damaged skin of lupus patients, suggesting that the reduced numbers of pDCs in blood could be in part explained by the rapid migration to inflamed tissues $(64,65)$. By using different lupus mouse models, such as (NZBxNZW)F1 mice, BXSB.DTR mice or Tlr7.Tg animals, it has been seen that depletion of pDCs ameliorates SLE manifestations and inflammation, suggesting that targeting the function or accumulation of pDCs in tissues could be a viable therapy to ameliorate SLE (66-68).

\section{Basophils}

Basophils are the rarest immune cell population in the blood, representing only $1 \%$ of circulating leukocytes. Initially implicated in allergic events and parasite infections, increasing evidence has suggested a role of basophils in $\operatorname{SLE}(69,70)$. Basophils are recruited into skin lesions of SLE patients, where they are implicated in promoting tissue damage (71). Data from a retrospective clinical study suggest that blood basophils could be potentially used as a biomarkers of disease activity in SLE $(72,73)$. By using the $\mathrm{Lyn}^{-/-}$mice, that develop a lupus-like disease late in life, Charles et al. showed that basophils are key players in promoting inflammation and supporting ANA production by B cells (69). Although initially controversial (74), this concept of basophils and SLE has been expanded in the recent years by studies showing that basophils derived from human SLE patients are able to promote antibody production by $B$ cells and support IL-17-producing $\mathrm{T}_{\mathrm{H}} 17$ differentiation of $\mathrm{T}$ cells in vitro (70). In line with the importance of basophils in SLE development, a very recent study has shown that Prostaglandin $\mathrm{D}_{2}\left(\mathrm{PGD}_{2}\right)$, an important inflammatory mediator, is elevated in plasma from SLE patients and through the interaction with $\mathrm{PGD}_{2}$ receptors expressed by blood basophils, leads to basophils accumulation in secondary lymphoid organs (75). Moreover, $\mathrm{PGD}_{2}$ receptors blockade leads to the reduction of basophils migration into secondary lymphoid organs, dampening lupuslike disease activity in $\mathrm{Lyn}^{-/-}$mice (75). Whether basophils could be a suitable therapeutic target in SLE remains to be evaluated.

\section{Innate Lymphoid Cells}

Described about 10 years ago, ILCs represent an emerging family of innate immune cells. ILCs lack of antigen-specific receptors that are expressed by $\mathrm{B}$ and $\mathrm{T}$ cells, have a lymphoidlike morphology, and share cytotoxic and immunomodulatory capacities with cytotoxic $\mathrm{CD}^{+}$and helper $\mathrm{CD} 4^{+} \mathrm{T}$ cells (76). Current classification of ILCs is based on their transcription factors and cytokine production profile: NK cells, expressing the transcription factor EOMES with unique cytotoxic capacities; group 1 ILCs that express the transcription factor T-bet and produce IFN- $\gamma$; group 2 ILCs that express $\operatorname{ROR} \alpha$ and GATA 3 and produce type 2 cytokines (e.g., IL-4, IL5, IL-9, and IL-13); and group 3 ILCs that express the transcription factor ROR $\gamma \mathrm{t}$ and produce IL-17A and IL22 (77, 78). Recently, a link between ILCs and SLE has been found in an animal model, where reduced numbers of renal-infiltrating ILC2s were observed in the MRL/MpFaslpr (lpr) lupus mouse model (79). The reduction was also observed as disease progresses. More interestingly, restoring ILC2 numbers by treatment with IL-33 reduces immune cell infiltration in the kidney glomerulus and improves survival (79). These findings are consistent with a recent study showing that circulating ILC1s and ILC3s are increased, whereas ILC2s numbers are reduced in SLE patients (80). Although more studies are needed to confirm and expand upon these observations, manipulation of the numbers, and functions of ILCs could be a good candidate for future therapeutic approaches.

\section{Molecular Regulators of Innate Immunity: The Complement System, Cytokines, and Toll-Like Receptors (TLRs)}

Another important innate immune component is the complement cascade. Consisting of more than 30 proteins, the activation of the complement cascade leads to the production of opsonins and chemoattractant cytokines, promotes the production of antibodies, and drives the clearance of immune complexes, apoptotic cells and debris (81). Individuals who are deficient in the early complement proteins $\mathrm{C} 1$ and $\mathrm{C} 4$ are highly susceptible to developing SLE, with C1q deficiency a stronger genetic predictor to the disease $(93 \%$ of individuals 


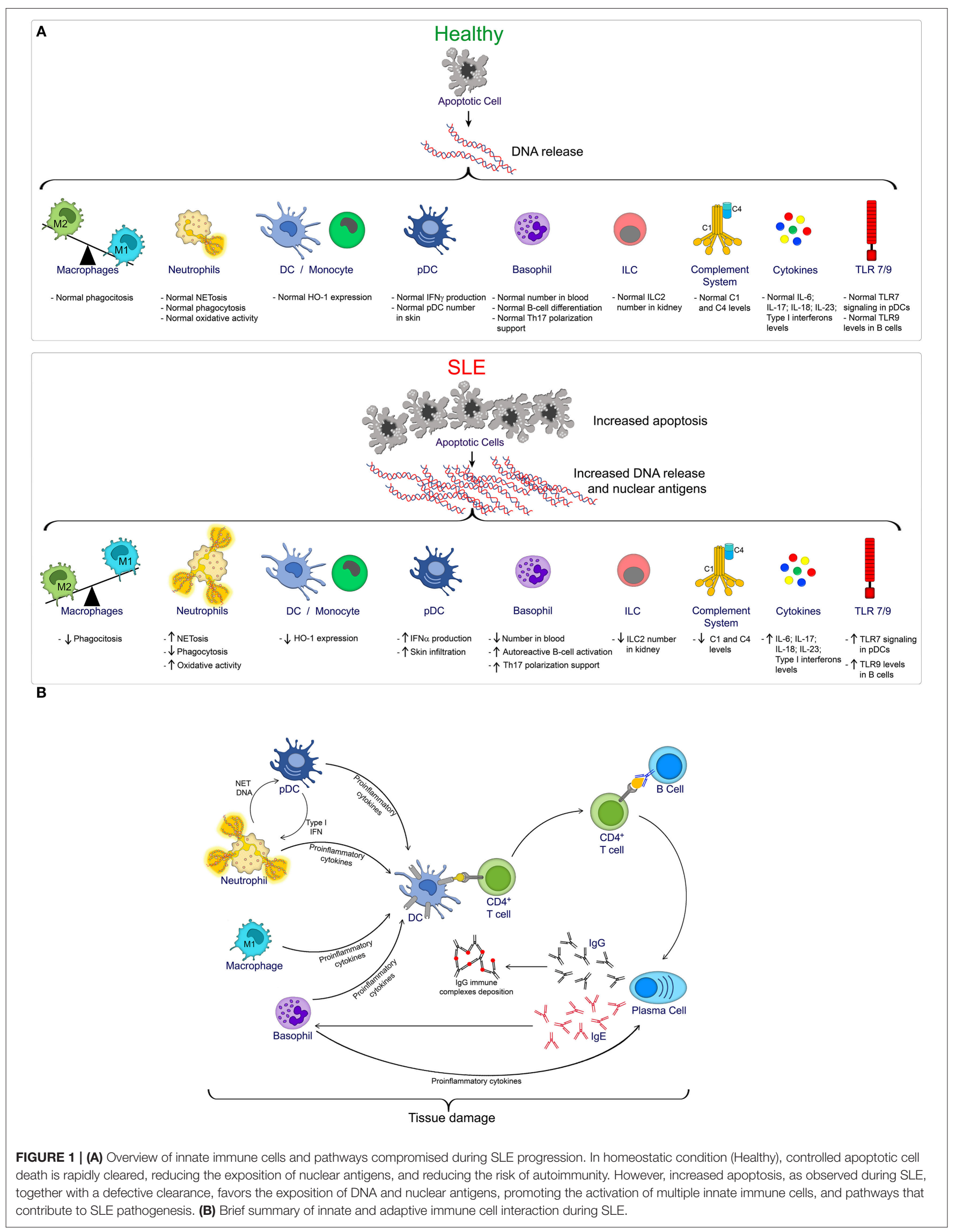


with C1q deficiency, and 75\% of individuals with C4 deficiency present SLE-like symptoms) (82). Mice deficient for C1q or C4 are also predisposed to develop SLE-like disease $(83,84)$. Two hypotheses have emerged to explain these observations. One called the "waste disposal hypothesis," suggests that the complement cascade eliminates apoptotic cells and debris, therefore preventing the accumulation of self-antigens that could activate adaptive immune cells (83). The second "tolerance hypothesis" states that the complement cascade is important to generate $\mathrm{B}$-cell tolerance by eliminating autoreactive $\mathrm{B}$ cells (85). Interestingly, deficiency of C3, another early component of the cascade, is not associated with SLE development (86). Recently, a study from Botto's group suggested that C1q, but not $\mathrm{C} 3$, can promote metabolic changes in $\mathrm{CD}^{+} \mathrm{T}$ cells, regulating their function and reducing autoimmunity damage, thereby partially clarifying the discrepancy between C1q and C3 deficiency (87). These observations suggest $\mathrm{C} 1 \mathrm{q}$ as a potential therapeutic target, but more studies are needed to evaluate this idea.

There is also growing evidence supporting the pathogenic role of cytokines in this disease. Examples of these cytokines include BLyS, IL-6, IL-17, IL-18, type I IFNs, and TNF- $\alpha$ (88). Cytokines regulate and control the immune system. In SLE, several of these cytokines are overexpressed and contribute to the pathogenesis of disease. Cytokine inhibition has been successfully used to treat other rheumatic and autoimmune diseases, and several cytokines are currently being investigated to determine whether inhibition would be therapeutic in lupus. Several cytokines are undergoing clinical trials, including TNF- $\alpha$, IL-1, IL-6, IL-10, IL15, IL-17, IL-18, and IL-23. While current trials have not proven efficacy (Table 1), cytokine targeting is still a promising strategy to ameliorate SLE progression (89).

Toll-like receptors (TLRs), a group of glycoproteins that function as surface or endoplasmic trans-membrane receptors, are involved in the innate and adaptive immune responses to exogenous pathogenic microorganisms. TLRs are widely expressed in immune cells (neutrophils, monocytes/macrophages, lymphocytes and DCs), and their activation leads to an inflammatory response by recognizing pathogen and danger-associated molecular patterns (PAMPs and DAMPS). TLRs are a key link between infection, injury and inflammation (90). Although TLR-mediated inflammation is an important aspect of host defense, it is also associated with the pathogenesis of SLE (91). Since self-DNA and selfRNA can form protein complexes and serve as TLR9 and TLR7 ligands, respectively, TLR stimulation may contribute to activation and/or modulation of the immune response $(92,93)$. The numbers of human peripheral blood B cells and monocytes expressing TLR9 are elevated in patients with SLE, and this increased expression correlated with increased complement function and SLE disease severity (90, 94). Regarding TLR7, a recent study has shown that pDCs derived from SLE patients have increased IFN- $\alpha$ production after TLR7 stimulation compared to $\mathrm{pDCs}$ derived from healthy donors (95). Mechanistically, TLR7 is retained in late endosome/lysosome compartments in pDCs from SLE patients, increasing TLR7 signaling and IFN- $\alpha$ production (95). Moreover, in a systematic review and meta-analysis, TLR7 and TLR9 polymorphisms were shown to be associated with the development of SLE in Asian populations (96). Additionally, increased expression of other TLRs, such as TLR2, TLR3, TLR4, or TLR5 has been observed in immune cells or biopsies of SLE patients, and studies in animals models have suggested the importance of these TLRs in promoting SLE pathogenesis (97-102). The accumulation of evidence for TLRs in autoimmunity has opened the door for potential therapeutic interventions directed toward the modulation of TLRs and their signaling pathways (103). A summary of innate immune components involved in SLE pathogenesis and the interaction between innate and adaptive immune cells during SLE is shown in Figure 1.

\section{CONCLUDING REMARKS}

Despite the importance of adaptive immune responses mediated by $\mathrm{B}$ and $\mathrm{T}$ cells during SLE pathogenesis, the role of innate immune components has been only recently addressed. Now, we know that a complex network of innate and adaptive immune cells interactions occurs during SLE. This complexity allows scientists and clinical researchers to explore a wide source of possible new therapeutics targets. We predict that new studies will continue to show the importance of innate immune components during SLE. These analyses will provide the groundwork for new therapeutic approaches that modulate innate immune cells accumulation or function as new strategies to limit or ameliorate SLE pathology.

\section{AUTHOR CONTRIBUTIONS}

$\mathrm{AH}, \mathrm{LC}$, and $\mathrm{CL}$ wrote the manuscript. NE made the figure. RV made the table. AH, NE, MI, RV, PB, LC, and CL read, discussed, and revised the manuscript. All authors listed have made a substantial, direct and intellectual contribution to the work, and approved it for publication.

\section{FUNDING}

This study was supported in part by the Projects: Redes Internacionales (REDI170651) (to $\mathrm{AH}$ and MI); Proyecto interno Universidad Autónoma de Chile (DIUA 134-2018) and by the Pilot Research Grant (PP-1805-30965) from the National Multiple Sclerosis Society (to AH); Proyecto GeneraAutónoma $\mathrm{N}^{\circ}$ UA 17-04 and FONDECYT de Inicio $\mathrm{N}^{\circ} 11160592$, CONICYT (to NE) and Proyecto Vicerrectoría de Investigación, Pontificia Universidad Católica de Chile Puente P1802 (to CL).

\section{ACKNOWLEDGMENTS}

We acknowledge Dr. Nicole M. Chapman (St. Jude Children's Research Hospital), for critical reading of the manuscript. 


\section{REFERENCES}

1. Ding C, Foote S, Jones G. B-cell-targeted therapy for systemic lupus erythematosus: an update. BioDrugs. (2008) 22:239-49. doi: 10.2165/00063030-200822040-00003

2. Kalunian K, Merrill JT. New directions in the treatment of systemic lupus erythematosus. Curr Med Res Opin. (2009) 25:1501-14. doi: 10.1185/03007990902929104

3. Crispín JC, Liossis SN, Kis-Toth K, Lieberman LA, Kyttaris VC, Juang YT et al. Tsokos: pathogenesis of human systemic lupus erythematosus: recent advances. Trends Mol Med. (2010) 16:47-57. doi: 10.1016/j.molmed.2009.12.005

4. Perl A, Fernandez DR, Telarico T, Doherty E, Francis L, Phillips PE. T-cell and B-cell signaling biomarkers and treatment targets in lupus. Curr Opin Rheumatol. (2009) 21:454-64. doi: 10.1097/BOR.0b013e32832e977c

5. Dema B, Charles N. Advances in mechanisms of systemic lupus erythematosus. Discov Med. (2014) 17:247-55.

6. Liossis SC, Staveri C. B cell-based treatments in SLE: past experience and current directions. Curr Rheumatol Rep. (2017) 19:78. doi: 10.1007/s11926-017-0707-z

7. Melander C, Sallée M, Trolliet P, Candon S, Belenfant X, Daugas E, et al. Rituximab in severe lupus nephritis: early B-cell depletion affects long-term renal outcome. Clin J Am Soc Nephrol. (2009) 4:579-87. doi: $10.2215 /$ CJN.04030808

8. Duxbury B, Combescure C, Chizzolini C. Rituximab in systemic lupus erythematosus: an updated systematic review and meta-analysis. Lupus. (2013) 22:1489-503. doi: 10.1177/0961203313509295

9. Cassia M, Alberici F, Gallieni M, Jayne D. Lupus nephritis and Bcell targeting therapy. Expert Rev Clin Immunol. (2017) 13:951-62. doi: 10.1080/1744666X.2017.1366855

10. Austin HA, Klippel J, Balow J, le Riche N, Steinberg A, Plotz P, et al. Therapy of lupus nephritis. Controlled trial of prednisone and cytotoxic drugs. N Engl J Med. (1986) 314:614-9. doi: 10.1056/NEJM198603063141004

11. Chen Y, Sun J, Zou K, Yang Y, Liu G. Treatment for lupus nephritis: an overview of systematic reviews and meta-analyses. Rheumatol Int. (2017) 37:1089-99. doi: 10.1007/s00296-017-3733-2

12. Tang K, Tseng C, Hsieh T, Chen D. Induction therapy for membranous lupus nephritis: a systematic review and network meta-analysis. Int J Rheum Dis. (2018) 21:1163-72. doi: 10.1111/1756-185X.13321

13. Tunnicliffe D, Palmer S, Henderson L, Masson P, Craig J, Tong $\mathrm{A}$, et al. Immunosuppressive treatment for proliferative lupus nephritis. Cochrane Database Syst Rev. (2018) 6:CD002922. doi: 10.1002/14651858.CD002922.pub4

14. Mahmoud I, Jellouli M, Boukhris I, Charfi R, Ben Tekaya A, Saidane O, et al. Efficacy and safety of rituximab in the management of pediatric systemic lupus erythematosus: a systematic review. J Pediatr. (2017) 187:213-9.e2. doi: 10.1016/j.jpeds.2017.05.002

15. Ginzler E, Dooley M, Aranow C, Kim M, Buyon J, Merrill J, et al. Mycophenolate mofetil or intravenous cyclophosphamide for lupus nephritis. N Engl J Med. (2005) 353:2219-28. doi: 10.1056/NEJMoa043731

16. Sinclair A, Appel G, Dooley M, Ginzler E, Isenberg D, Jayne D, et al. Mycophenolate mofetil as induction and maintenance therapy for lupus nephritis: rationale and protocol for the randomized, controlled Aspreva Lupus Management Study (ALMS). Lupus. (2007) 16:972-80. doi: 10.1177/0961203307084712

17. Balow J, Austin HA, Muenz L, Joyce K, Antonovych T, Klippel J, et al. Effect of treatment on the evolution of renal abnormalities in lupus nephritis. $N$ Engl J Med. (1984) 311:491-5. doi: 10.1056/NEJM198408233110802

18. Tian M, Song X, Dong L, Xin X, Dong J. Systematic evaluation of different doses of cyclophosphamide induction therapy for lupus nephritis. Medicine. (2017) 96:e9408. doi: 10.1097/MD.0000000000009408

19. Merrill J, Buyon J, Furie R, Latinis K, Gordon C, Hsieh H, et al. Assessment of flares in lupus patients enrolled in a phase II/III study of rituximab (EXPLORER). Lupus. (2011) 20:709-16. doi: 10.1177/09612033103 95802

20. Vital E, Dass S, Buch M, Henshaw K, Pease C, Martin M, et al. B cell biomarkers of rituximab responses in systemic lupus erythematosus. Arthritis Rheum. (2011) 63:3038-47. doi: 10.1002/art.30466
21. Navarra S, Guzman R, Gallacher A, Hall S, Levy R, Jimenez R, et al. Efficacy and safety of belimumab in patients with active systemic lupus erythematosus: a randomised, placebo-controlled, phase 3 trial. Lancet. (2011) 377:721-31. doi: 10.1016/S0140-6736(10)61354-2

22. Stohl W, Schwarting A, Okada M, Scheinberg M, Doria A, Hammer A, et al. Efficacy and safety of subcutaneous belimumab in systemic lupus erythematosus: a fifty-two-week randomized, double-blind, placebo-controlled study. Arthritis Rheumatol. (2017) 69:1016-27. doi: 10.1002/art.40049

23. Doria A, Bass D, Schwarting A, Hammer A, Gordon D, Scheinberg M, et al. A 6-month open-label extension study of the safety and efficacy of subcutaneous belimumab in patients with systemic lupus erythematosus. Lupus. (2018) 27:1489-98. doi: 10.1177/0961203318777634

24. Li Y, Lee PY, Reeves WH. Monocyte and macrophage abnormalities in systemic lupus erythematosus. Arch Immunol Ther Exp. (2010) 58:355-64. doi: 10.1007/s00005-010-0093-y

25. Katsiari CG, Liossis SN, Sfikakis PP. The pathophysiologic role of monocytes and macrophages in systemic lupus erythematosus: a reappraisal. Semin Arthritis Rheum. (2010) 39:491-503. doi: 10.1016/j.semarthrit.2008.11.002

26. Bijl M, Reefman E, Horst G, Limburg PC, Kallenberg CG. Reduced uptake of apoptotic cells by macrophages in systemic lupus erythematosus: correlates with decreased serum levels of complement. Ann Rheum Dis. (2006) 65:5763. doi: 10.1136/ard.2005.035733

27. Tas SW, Quartier P, Botto M, Fossati-Jimack L. Macrophages from patients with SLE and rheumatoid arthritis have defective adhesion in vitro, while only SLE macrophages have impaired uptake of apoptotic cells. Ann Rheum Dis. (2006) 65:216-21. doi: 10.1136/ard.2005.037143

28. Mantovani A, Sica A, Sozzani S, Allavena P, Vecchi A, Locati M. The chemokine system in diverse forms of macrophage activation and polarization. Trends Immunol. (2004) 25:677-86. doi: 10.1016/j.it.2004.09.015

29. Labonte AC, Kegerreis B, Geraci NS, Bachali P, Madamanchi S, Robl R, et al. Grammer: Identification of alterations in macrophage activation associated with disease activity in systemic lupus erythematosus. PLOS ONE. (2018) 13:e0208132. doi: 10.1371/journal.pone.0208132

30. Mohammadi S, Saghaeian-Jazi M, Sedighi S, Memarian A. Immunomodulation in systemic lupus erythematosus: induction of M2 population in monocyte-derived macrophages by pioglitazone. Lupus. (2017) 26:1318-27. doi: 10.1177/0961203317701842

31. Li F, Yang Y, Zhu X, Huang L, Xu J. Macrophage polarization modulates development of systemic lupus erythematosus. Cell Physiol Biochem. (2015) 37:1279-88. doi: 10.1159/000430251

32. Almaani S, Meara A, Rovin BH. Update on lupus nephritis. Clin J Am Soc Nephrol. (2017) 12:825-35. doi: 10.2215/CJN.05780616

33. Iwata Y, Boström EA, Menke J, Rabacal WA, Morel L, Wada T, et al. Aberrant macrophages mediate defective kidney repair that triggers nephritis in lupus-susceptible mice. J Immunol. (2012) 188:4568-80. doi: 10.4049/jimmunol.1102154

34. Brandt L, Hedberg H. Impaired phagocytosis by peripheral blood granulocytes in systemic lupus erythematosus. Scand J Haematol. (1969) 6:348-53. doi: 10.1111/j.1600-0609.1969.tb02420.x

35. Donnelly S, Roake W, Brown S, Young P, Naik H, Wordsworth P, et al. Impaired recognition of apoptotic neutrophils by the $\mathrm{C} 1 \mathrm{q} /$ calreticulin and CD91 pathway in systemic lupus erythematosus. Arthritis Rheum. (2006) 54:1543-56. doi: 10.1002/art.21783

36. Alves CM, Marzocchi-Machado CM, Louzada-Junior P, Azzolini AE, Polizello AC, de Carvalho IF, et al. Superoxide anion production by neutrophils is associated with prevalent clinical manifestations in systemic lupus erythematosus. Clin Rheumatol. (2008) 27:701-8. doi: 10.1007/s10067-007-0768-x

37. Gupta S, Kaplan MJ. The role of neutrophils and NETosis in autoimmune and renal diseases. Nat Rev Nephrol. (2016) 12:402-13. doi: 10.1038/nrneph.2016.71

38. Brinkmann V, Reichard U, Goosmann C, Fauler B, Uhlemann Y, Weiss DS, et al. Neutrophil extracellular traps kill bacteria. Science. (2004) 303:1532-5. doi: 10.1126/science.1092385

39. Garcia-Romo GS, Caielli S, Vega B, Connolly J, Allantaz F, Xu Z, et al. Netting neutrophils are major inducers of type I IFN production in 
pediatric systemic lupus erythematosus. Sci Transl Med. (2011) 3:73ra20. doi: 10.1126/scitranslmed.3001201

40. Lande R, Ganguly D, Facchinetti V, Frasca L, Conrad C, Gregorio J, et al. Neutrophils activate plasmacytoid dendritic cells by releasing self-DNApeptide complexes in systemic lupus erythematosus. Sci Transl Med. (2011) 3:73ra19. doi: 10.1126/scitranslmed.3001180

41. Dieker J, Tel J, Pieterse E, Thielen A, Rother N, Bakker M, et al. Circulating apoptotic microparticles in systemic lupus erythematosus patients drive the activation of dendritic cell subsets and prime neutrophils for NETosis. Arthritis Rheumatol. (2016) 68:462-72. doi: 10.1002/art.39417

42. Villanueva E, Yalavarthi S, Berthier CC, Hodgin JB, Khandpur R, Lin AM, et al. Netting neutrophils induce endothelial damage, infiltrate tissues, and expose immunostimulatory molecules in systemic lupus erythematosus. $J$ Immunol. (2011) 187:538-52. doi: 10.4049/jimmunol.1100450

43. Hakkim A, Fürnrohr BG, Amann K, Laube B, Abed UA, Brinkmann $\mathrm{V}$, et al. Impairment of neutrophil extracellular trap degradation is associated with lupus nephritis. Proc Natl Acad Sci USA. (2010) 107:9813-8. doi: 10.1073/pnas.0909927107

44. Kato Y, Park J, Takamatsu H, Konaka H, Aoki W, Aburaya S, et al. Apoptosisderived membrane vesicles drive the cGAS-STING pathway and enhance type I IFN production in systemic lupus erythematosus. Ann Rheum Dis. (2018) 77:1507-15. doi: 10.1136/annrheumdis-2018-212988

45. Marian V, Anolik JH. Treatment targets in systemic lupus erythematosus: biology and clinical perspective. Arthritis Res Ther. (2012) 14 (Suppl. 4):S3. doi: $10.1186 /$ ar3917

46. Llanos C, Carreño LJ, Kalergis AM. Contribution of dendritic cell/T cell interactions to triggering and maintaining autoimmunity. Biol Res. (2011) 44:53-61. doi: 10.4067/S0716-97602011000100007

47. Llanos C, Mackern-Oberti JP, Vega F, Jacobelli SH, Kalergis AM. Tolerogenic dendritic cells as a therapy for treating lupus. Clin Immunol. (2013) 148:23745. doi: 10.1016/j.clim.2013.04.017

48. Llanos C, Carreño LJ, Gutierrez MA, Riedel CA, Jacobelli SH, Kalergis AM. Genetic and pharmacological modulation of dendritic cell-T cell interactions as a therapeutic strategy for systemic lupus erythematosus. Curr Gene Ther. (2011) 11:544-53. doi: 10.2174/156652311798192806

49. Obreque J, Vega F, Torres A, Cuitino L, Mackern-Oberti JP, Viviani P, et al. Autologous tolerogenic dendritic cells derived from monocytes of systemic lupus erythematosus patients and healthy donors show a stable and immunosuppressive phenotype. Immunology. (2017) 152:648-59. doi: $10.1111 / \mathrm{imm} .12806$

50. Herrada AA, Llanos C, Mackern-Oberti JP, Carreño LJ, Henriquez C, Gómez RS, et al. Haem oxygenase 1 expression is altered in monocytes from patients with systemic lupus erythematosus. Immunology. (2012) 136:41424. doi: $10.1111 / j .1365-2567.2012 .03598 . x$

51. Mackern-Oberti JP, Llanos C, Carreño LJ, Riquelme SA, Jacobelli SH, Anegon I, et al. Carbon monoxide exposure improves immune function in lupusprone mice. Immunology. (2013) 140:123-32. doi: 10.1111/imm.12124

52. Mackern-Oberti JP, Riquelme SA, Llanos C, Schmidt CB, Simon T, Anegon I, et al. Heme oxygenase- 1 as a target for the design of gene and pharmaceutical therapies for autoimmune diseases. Curr Gene Ther. (2014) 14:218-35. doi: 10.2174/1566523214666140424150308

53. Mackern-Oberti JP, Vega F, Llanos C, Bueno SM, Kalergis AM. Targeting dendritic cell function during systemic autoimmunity to restore tolerance. Int J Mol Sci. (2014) 15:16381-417. doi: 10.3390/ijms150916381

54. Mackern-Oberti JP, Obreque J, Méndez GP, Llanos C, Kalergis AM. Carbon monoxide inhibits $\mathrm{T}$ cell activation in target organs during systemic lupus erythematosus. Clin Exp Immunol. (2015) 182:1-13. doi: 10.1111/cei.12657

55. Aparicio-Soto M, Sánchez-Hidalgo M, Cárdeno A, Rosillo M, SánchezFidalgo S, Utrilla J, et al. Dietary extra virgin olive oil attenuates kidney injury in pristane-induced SLE model via activation of HO-1/Nrf-2 antioxidant pathway and suppression of JAK/STAT, NF-KB and MAPK activation. J Nutr Biochem. (2016) 27:278-88. doi: 10.1016/j.jnutbio.2015.09.017

56. Liu YJ. IPC: professional type 1 interferon-producing cells and plasmacytoid dendritic cell precursors. Annu Rev Immunol. (2005) 23:275-306. doi: 10.1146/annurev.immunol.23.021704.115633

57. Ytterberg SR, Schnitzer TJ. Serum interferon levels in patients with systemic lupus erythematosus. Arthritis Rheum. (1982) 25:401-6. doi: 10.1002/art.1780250407
58. Hooks JJ, Moutsopoulos HM, Geis SA, Stahl NI, Decker JL, Notkins AL. Immune interferon in the circulation of patients with autoimmune disease. N Engl J Med. (1979) 301:5-8. doi: 10.1056/NEJM197 907053010102

59. Harley JB, Alarcón-Riquelme ME, Criswell LA, Jacob CO, Kimberly RP, Moser KL, et al. Genome-wide association scan in women with systemic lupus erythematosus identifies susceptibility variants in ITGAM, PXK, KIAA1542 and other loci. Nat Genet. (2008) 40:204-10. doi: 10.1038/ ng. 81

60. Hom G, Graham RR, Modrek B, Taylor KE, Ortmann W, Garnier S, et al. Association of systemic lupus erythematosus with C8orf13BLK and ITGAM-ITGAX. N Engl J Med. (2008) 358:900-9. doi: 10.1056/NEJMoa0707865

61. Vallin H, Blomberg S, Alm GV, Cederblad B, Rönnblom L. Patients with systemic lupus erythematosus (SLE) have a circulating inducer of interferon-alpha (IFN-alpha) production acting on leucocytes resembling immature dendritic cells. Clin Exp Immunol. (1999) 115:196-202. doi: 10.1046/j.1365-2249.1999.00772.x

62. Rönnblom L, Alm GV. A pivotal role for the natural interferon alphaproducing cells (plasmacytoid dendritic cells) in the pathogenesis of lupus. J Exp Med. (2001) 194:F59-63. doi: 10.1084/jem.194.12.f59

63. Liao X, Li S, Settlage RE, Sun S, Ren J, Reihl AM, et al. Cutting edge: plasmacytoid dendritic cells in late-stage lupus mice defective in producing IFN- $\alpha$. J Immunol. (2015) 195:4578-82. doi: 10.4049/ jimmunol.1501157

64. Blanco P, Palucka AK, Gill M, Pascual V, Banchereau J. Induction of dendritic cell differentiation by IFN-alpha in systemic lupus erythematosus. Science. (2001) 294:1540-3. doi: 10.1126/science.1064890

65. Farkas L, Beiske K, Lund-Johansen F, Brandtzaeg P, Jahnsen FL. Plasmacytoid dendritic cells (natural interferon- alpha/beta-producing cells) accumulate in cutaneous lupus erythematosus lesions. Am J Pathol. (2001) 159:237-43. doi: 10.1016/S0002-9440(10)61689-6

66. Guiducci C, Tripodo C, Gong M, Sangaletti S, Colombo MP, Coffman RL, et al. Autoimmune skin inflammation is dependent on plasmacytoid dendritic cell activation by nucleic acids via TLR7 and TLR9. J Exp Med. (2010) 207:2931-42. doi: 10.1084/jem.20101048

67. Rowland SL, Riggs JM, Gilfillan S, Bugatti M, Vermi W, Kolbeck R, et al. Early, transient depletion of plasmacytoid dendritic cells ameliorates autoimmunity in a lupus model. J Exp Med. (2014) 211:1977-91. doi: $10.1084 /$ jem. 20132620

68. Sisirak V, Ganguly D, Lewis KL, Couillault C, Tanaka L, Bolland S, et al. Genetic evidence for the role of plasmacytoid dendritic cells in systemic lupus erythematosus. J Exp Med. (2014) 211:1969-76. doi: $10.1084 /$ jem.20132522

69. Charles N, Hardwick D, Daugas E, Illei GG, Rivera J. Basophils and the T helper 2 environment can promote the development of lupus nephritis. Nat Med. (2010) 16:701-7. doi: 10.1038/nm.2159

70. Pan Q, Gong L, Xiao H, Feng Y, Li L, Deng Z, et al. Basophil activation-dependent autoantibody and interleukin-17 production exacerbate systemic lupus erythematosus. Front Immunol. (2017) 8:348. doi: 10.3389/fimmu.2017.00348

71. Pan Q, Feng Y, Peng Y, Zhou H, Deng Z, Li L, et al. Basophil recruitment to skin lesions of patients with systemic lupus erythematosus mediated by CCR1 and CCR2. Cell Physiol Biochem. (2017) 43:832-9. doi: $10.1159 / 000481609$

72. Liang P, Tang Y, Fu S, Lv J, Liu B, Feng M, et al. Basophil count, a marker for disease activity in systemic lupus erythematosus. Clin Rheumatol. (2015) 34:891-6. doi: 10.1007/s10067-014-2822-9

73. Liang P, Tang Y, Lin L, Zhong H, Yang H, Zeng Y, et al. Low level of circulating basophil counts in biopsy-proven active lupus nephritis. Clin Rheumatol. (2018) 37:459-65. doi: 10.1007/s10067-017-3858-4

74. Dijkstra D, Hennig C, Witte T, Hansen G. Basophils from humans with systemic lupus erythematosus do not express MHC-II. Nat Med. (2012) 18:488-9; author reply 489-90. doi: 10.1038/nm.2663

75. Pellefigues C, Dema B, Lamri Y, Saidoune F, Chavarot N, Lohéac C, et al. Prostaglandin D2 amplifies lupus disease through basophil accumulation in lymphoid organs. Nat Commun. (2018) 9:725. doi: $10.1038 /$ s41467-018-03129-8 
76. Vivier E, Artis D, Colonna M, Diefenbach A, Di Santo JP, Eberl G, et al. Innate Lymphoid Cells: 10 Years On. Cell. (2018) 174:1054-66. doi: $10.1016 /$ j.cell.2018.07.017

77. Artis D, Spits H. The biology of innate lymphoid cells. Nature. (2015) 517:293-301. doi: 10.1038/nature14189

78. Zook EC, Kee BL. Development of innate lymphoid cells. Nat Immunol. (2016) 17:775-82. doi: 10.1038/ni.3481

79. Düster M, Becker M, Gnirck AC, Wunderlich M, Panzer U, Turner JE. T cell-derived IFN- $\gamma$ downregulates protective group 2 innate lymphoid cells in murine lupus erythematosus. Eur J Immunol. (2018) 48:1364-75. doi: 10.1002/eji.201747303

80. Hou M, Liu S. Innate lymphoid cells are increased in systemic lupus erythematosus. Clin Exp Rheumatol. (2019). [Epub ahead of print].

81. Sarma JV, Ward PA. The complement system. Cell Tissue Res. (2011) 343:227-35. doi: 10.1007/s00441-010-1034-0

82. Arason GJ, Jorgensen GH, Ludviksson BR. Primary immunodeficiency and autoimmunity: lessons from human diseases. Scand J Immunol. (2010) 71:317-28. doi: 10.1111/j.1365-3083.2010.02386.x

83. Botto M, Dell'Agnola C, Bygrave AE, Thompson EM, Cook HT, Petry F, et al. Homozygous $\mathrm{Clq}$ deficiency causes glomerulonephritis associated with multiple apoptotic bodies. Nat Genet. (1998) 19:56-9. doi: 10.1038/ng0598-56

84. Paul E, Pozdnyakova OO, Mitchell E, Carroll MC. Anti-DNA autoreactivity in C4-deficient mice. Eur J Immunol. (2002) 32:2672-9. doi: 10.1002/1521-4141(200209)32:9<2672::AID-IMMU2672>3.0.CO;2-X

85. Carroll MC. A protective role for innate immunity in systemic lupus erythematosus. Nat Rev Immunol. (2004) 4:825-31. doi: 10.1038/nri1456

86. Degn SE, Jensenius JC, Thiel S. Disease-causing mutations in genes of the complement system. Am J Hum Genet. (2011) 88:689-705. doi: 10.1016/j.ajhg.2011.05.011

87. Ling GS, Crawford G, Buang N, Bartok I, Tian K, Thielens NM, et al. $\mathrm{C} 1 \mathrm{q}$ restrains autoimmunity and viral infection by regulating CD8. Science. (2018) 360:558-63. doi: 10.1126/science.aao4555

88. Yap DY, Lai KN. The role of cytokines in the pathogenesis of systemic lupus erythematosus - from bench to bedside. Nephrology. (2013) 18:243-55. doi: 10.1111/nep.12047

89. Clark DN, Markham JL, Sloan CS, Poole BD. Cytokine inhibition as a strategy for treating systemic lupus erythematosus. Clin Immunol. (2013) 148:335-43. doi: 10.1016/j.clim.2012.11.001

90. Migita K, Miyashita T, Maeda Y, Nakamura M, Yatsuhashi H, Kimura H, et al. Toll-like receptor expression in lupus peripheral blood mononuclear cells. $J$ Rheumatol. (2007) 34:493-500.

91. Lee PY, Kumagai Y, Li Y, Takeuchi O, Yoshida H, Weinstein J, et al. TLR7-dependent and FcgammaR-independent production of type I interferon in experimental mouse lupus. J Exp Med. (2008) 205:2995-3006. doi: 10.1084/jem.20080462

92. Chauhan SK, Singh VV, Rai R, Rai M, Rai G. Distinct autoantibody profiles in systemic lupus erythematosus patients are selectively associated with TLR7 and TLR9 upregulation. J Clin Immunol. (2013) 33:954-64. doi: 10.1007/s10875-013-9887-0

93. Celhar T, Magalhães R, Fairhurst AM. TLR7 and TLR9 in SLE: when sensing self goes wrong. Immunol Res. (2012) 53:58-77. doi: 10.1007/s12026-012-8270-1

94. Papadimitraki ED, Choulaki C, Koutala E, Bertsias G, Tsatsanis C, Gergianaki I, et al. Expansion of toll-like receptor 9-expressing B cells in active systemic lupus erythematosus: implications for the induction and maintenance of the autoimmune process. Arthritis Rheum. (2006) 54:360111. doi: 10.1002/art.22197

95. Murayama G, Furusawa N, Chiba A, Yamaji K, Tamura N, Miyake S. Enhanced IFN- $\alpha$ production is associated with increased TLR7 retention in the lysosomes of palasmacytoid dendritic cells in systemic lupus erythematosus. Arthritis Res Ther. (2017) 19:234. doi: 10.1186/s13075-017-1441-7

96. Lee YH, Lee HS, Choi SJ, Ji JD, Song GG. Associations between TLR polymorphisms and systemic lupus erythematosus: a systematic review and meta-analysis. Clin Exp Rheumatol. (2012) 30:262-5. doi: 10.1177/0961203315622823

97. Liu Y, Liao J, Zhao M, Wu H, Yung S, Chan TM, et al. Increased expression of TLR2 in CD4(+) T cells from SLE patients enhances immune reactivity and promotes IL-17 expression through histone modifications. Eur J Immunol. (2015) 45:2683-93. doi: 10.1002/eji.2014 45219

98. Klonowska-Szymczyk A, Wolska A, Robak T, Cebula-Obrzut B, Smolewski P, Robak E. Expression of toll-like receptors 3:7, and 9 in peripheral blood mononuclear cells from patients with systemic lupus erythematosus. Mediators Inflamm. (2014) 2014:381418. doi: 10.1155/ 2014/381418

99. Elloumi N, Fakhfakh R, Abida O, Ayadi L, Marzouk S, Hachicha H, et al. Relevant genetic polymorphisms and kidney expression of Toll-like receptor (TLR)-5 and TLR-9 in lupus nephritis. Clin Exp Immunol. (2017) 190:32839. doi: 10.1111/cei.13022

100. Lartigue A, Colliou N, Calbo S, François A, Jacquot S, Arnoult C, et al. Critical role of TLR2 and TLR4 in autoantibody production and glomerulonephritis in lpr mutation-induced mouse lupus. J Immunol. (2009) 183:6207-16. doi: 10.4049/jimmunol. 0803219

101. Patole PS, Gröne HJ, Segerer S, Ciubar R, Belemezova E, Henger A, et al. Viral double-stranded RNA aggravates lupus nephritis through Toll-like receptor 3 on glomerular mesangial cells and antigenpresenting cells. J Am Soc Nephrol. (2005) 16:1326-38. doi: 10.1681/ASN. 2004100820

102. Elloumi N, Fakhfakh R, Ayadi L, Sellami K, Abida O, Ben Jmaa M, et al. The increased expression of toll-like receptor 4 in renal and skin lesions in lupus erythematosus. J Histochem Cytochem. (2017) 65:389-98. doi: 10.1369/0022155417709234

103. Li J, Wang X, Zhang F, Yin H. Toll-like receptors as therapeutic targets for autoimmune connective tissue diseases. Pharmacol Ther. (2013) 138:441-51. doi: 10.1016/j.pharmthera.2013.03.003

Conflict of Interest Statement: The authors declare that the research was conducted in the absence of any commercial or financial relationships that could be construed as a potential conflict of interest.

Copyright (c) 2019 Herrada, Escobedo, Iruretagoyena, Valenzuela, Burgos, Cuitino and Llanos. This is an open-access article distributed under the terms of the Creative Commons Attribution License (CC BY). The use, distribution or reproduction in other forums is permitted, provided the original author(s) and the copyright owner(s) are credited and that the original publication in this journal is cited, in accordance with accepted academic practice. No use, distribution or reproduction is permitted which does not comply with these terms. 